\title{
Cultivo de ciruelas en Florida ${ }^{1}$
}

\author{
A. Sarkhosh, M. Olmstead, E. P. Miller, P. C. Andersen, J. G. Williamson y; traducción por Tatiana \\ Sanchez $z^{2}$
}

Las ciruelas podrían ser un cultivo potencial para los productores y propietarios de viviendas en Florida y otras áreas de invierno templado en toda la costa del Golfo, pero muchas variedades de ciruelas de la costa oeste no funcionarán de manera consistente en Florida para producir fruta. Sin embargo, el programa de mejoramiento de fruta de hueso de la Universidad de Florida ha desarrollado cultivares que mejoran el potencial para el cultivo de ciruelas en Florida y otras áreas de invierno templado que tienen alta presión de enfermedades. Estos cultivares se recomiendan para probar en Florida. Los nombres de todos los cultivares de ciruela de la Universidad de Florida comienzan con el prefijo 'Gulf'. Estos cultivares son ciruelas de tipo japonés (Prunus salicina Lindl.) y tienen resistencia al escaldado de hojas de ciruela (Xylella fastidiosa) y a la bacteriosis o cribado (Xanthomonas campestris). El tamaño del fruto es satisfactorio (aproximadamente 11/2 a 2 pulgadas de diámetro) con buena calidad del fruto. Maduran a principios o finales de mayo, aproximadamente dos semanas antes de que las ciruelas de otras áreas lleguen al mercado.

\section{Horas de frío y unidades de calor}

'Horas o unidades de frío' se refiere a las horas de temperatura por debajo de $45^{\circ} \mathrm{F}$ y por encima de $32^{\circ} \mathrm{F}$ que ocurren mientras el árbol está inactivo (Figura 1). Los árboles de hoja caduca requieren un cierto número de estas unidades para que los brotes vegetativos y florales se activen de manera oportuna y comiencen la temporada de crecimiento. Los árboles frutales con mayores requisitos de enfriamiento generalmente crecen bien y producen fruta en lugares más fríos, como la parte norte de Florida o los estados del norte. Si una ciruela adaptada a un área del norte se cultiva en Florida, no activará los brotes adecuadamente y no se adaptará a nuestro ciclo climático. La serie de ciruelos del 'Gulf' se ha desarrollado para adaptarse a nuestros inviernos suaves y fríos. Producirán fruta desde el área de Fort Myers hasta el norte de Florida, las regiones más bajas del sur de Georgia y las áreas más cálidas de los estados de la costa del Golfo de Méjico. Estas ciruelas florecen con las variedades de durazno de 150 horas de frío en Immokalee, los duraznos de 200-250 horas de frío en Orlando, las variedades de 250-350 horas de frío en Gainesville, y con los duraznos de 400-500 horas de frío en Quincy.

1. Este documento, HS895s, es uno de una serie de publicaciones del Departamento de Ciencias Hortícolas, Servicio de Extensión Cooperativa de la Florida, Instituto de Alimentos y Ciencias Agrícolas, Universidad de la Florida (UF/IFAS Extension). Fecha de primera publicación: marzo 2005. Revisado en abril 2012, enero 2016, y abril 2020. Visite nuestro sitio web EDIS en <https://edis.ifas.ufl.edu>.

2. A. Sarkhosh, profesor asistente y especialista en Extensión; M. Olmstead, exprofesor asistente, Departamento de Ciencias Hortícolas; E. P. Miller, ex biólogo, Departamento de Ciencias Hortícolas; P. C. Andersen, profesor retirado, Centro de Investigación y Educación del Norte de Florida; y J. G. Williamson, profesor; Departamento de Ciencias Hortícolas; UF/IFAS Extensión, Gainesville, FL 32611. La traducción del inglés al español estuvo a cargo de la Doctora en Medicina de Plantas, Tatiana Sanchez, Servicio de Extensión de UF/IFAS en el condado de Alachua. El mencionar un pesticida es para fines de identificación y no implica la aprobación de ese producto. Siempre lea y siga las instrucciones de la etiqueta de manera exacta cuando use cualquier pesticida. La información actual sobre el uso de pesticidas se puede obtener de su oficina local de Extensión de UF/IFAS.

El mencionar un pesticida es para fines de identificación y no implica la aprobación de ese producto. Siempre lea y siga las instrucciones de la etiqueta de manera exacta cuando use cualquier pesticida. La información actual sobre el uso de pesticidas se puede obtener de su oficina local de extensión de UF/ IFAS

The Institute of Food and Agricultural Sciences (IFAS) is an Equal Opportunity Institution authorized to provide research, educational information and other services

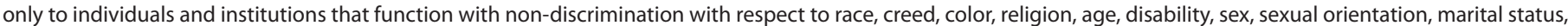

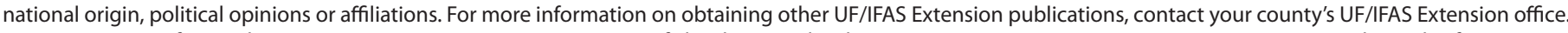
U.S. Department of Agriculture, UF/IFAS Extension Service, University of Florida, IFAS, Florida A \& M University Cooperative Extension Program, and Boards of County Commissioners Cooperating. Nick T. Place, dean for UF/IFAS Extension. 


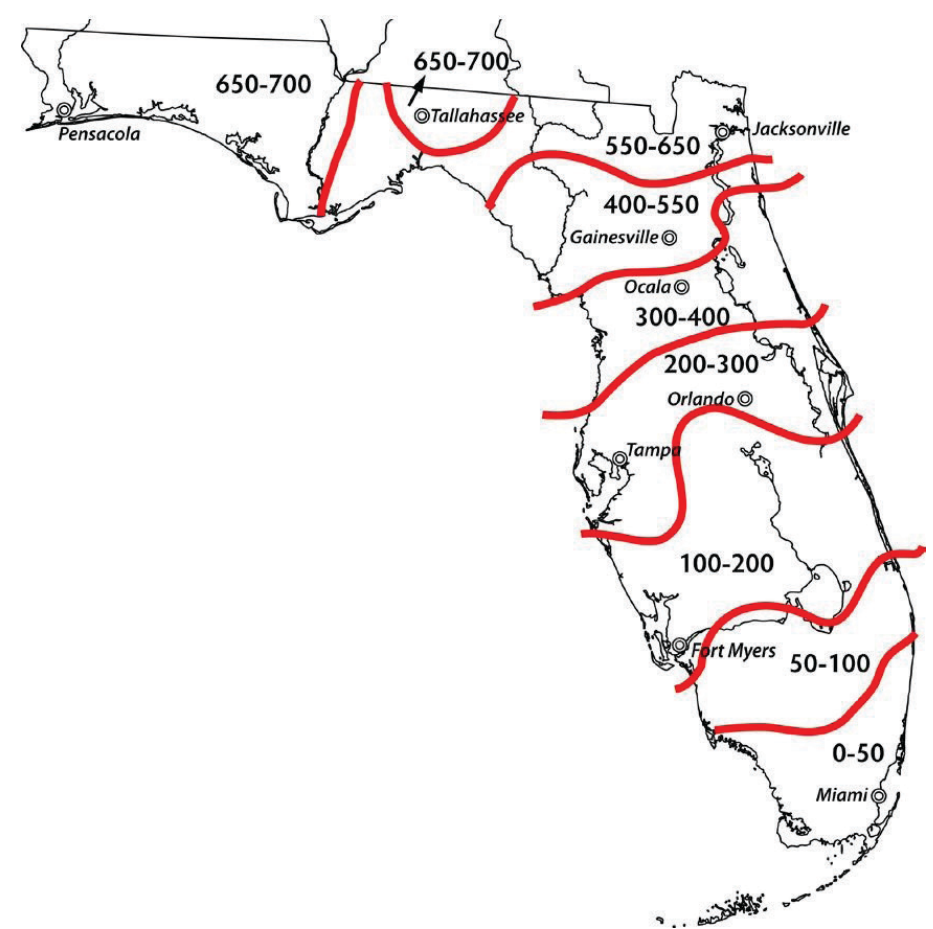

Figura 1. Promedio de acumulación de unidades de frío durante el invierno $\left(32^{\circ} \mathrm{F}-45^{\circ} \mathrm{F}\right)$ para el estado de Florida en el $75 \%$ de los inviernos.

Aunque las ciruelas de la serie 'Gulf' tienen un bajo requerimiento de enfriamiento, necesitan días más cálidos que los duraznos de bajo enfriamiento para romper la latencia invernal. Esta condición se conoce como un requisito de calor, que es un período de temperaturas nocturnas superiores a $55^{\circ} \mathrm{F}$ y temperaturas diurnas superiores a $65^{\circ} \mathrm{F}$. Para la serie de ciruelas 'Gulf', se requieren 1-2 semanas de estas condiciones para tener una brotación uniforme. Durante la mayoría de los inviernos en Florida, las ciruelas de la serie 'Gulf' no florecen lo suficientemente temprano como para ser demasiado susceptibles a la escarcha o a las heladas al final del invierno o principios de la primavera. Del mismo modo, no muestran síntomas de enfriamiento inadecuado, como floración o hojeado tardío que puede conducir a una reducción de la producción de fruta o la ausencia de fruta.

\section{Polinización y cuajado de la fruta}

Las ciruelas de la serie 'Gulf', como la mayoría de las ciruelas japonesas, no cuajan fruto por sí mismas y requieren polinización cruzada para el establecimiento de frutas (Figura 2). En general, cualquier cultivar será polinizado por un cultivar diferente siempre que su período de floración se superponga y los insectos polinizadores, como las abejas melíferas, estén activos. Las dos especies de ciruelas nativas, $P$. angustifolia (ciruela Chickasaw) y $P$. umbellata (ciruela de cerdo) o sus híbridos pueden servir como polinizadores, pero generalmente florecen antes que la serie
'Gulf' y su calidad de fruta es pobre. Los árboles para la polinización se plantan en una proporción de 1 polinizador por cada 5-8 árboles de cultivo. La capacidad de cultivo en las ciruelas 'Gulf' es muy alta y se debe hacer raleo (conocido también como aclareo) para obtener fruta grande y evitar que las ramas se rompan. La fruta se produce tanto en espuelas como a lo largo de los brotes de la temporada anterior. Estas ciruelas son precoces, a menudo fructifican en el segundo año después de la siembra.

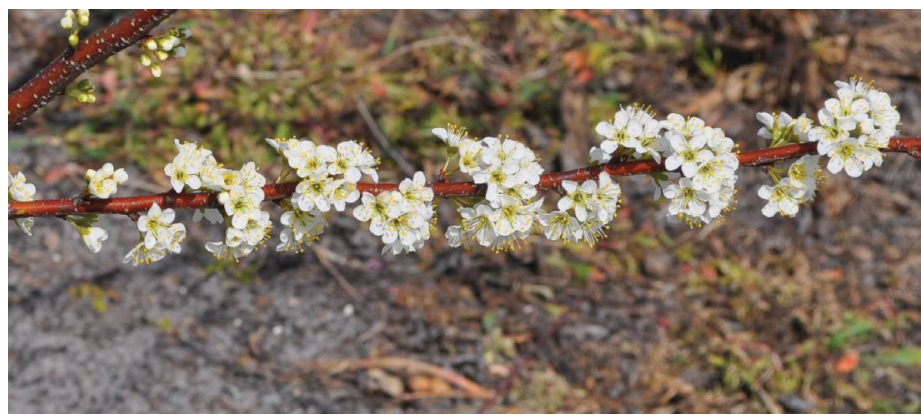

Figura 2. Flor de ciruela.

Créditos: M. Olmstead, UF/IFAS

\section{Período de desarrollo de la fruta}

El período de desarrollo de la fruta se refiere al período desde el cuajado durante la floración hasta la cosecha de la fruta. Se ve afectado por las temperaturas y puede acortarse por largos períodos de temperaturas superiores a la media y alargarse por largos períodos de temperaturas inferiores a la media. Típicamente, se usa como un indicador de cuándo se cosechará la fruta. Los períodos de floración para las ciruelas de la serie 'Gulf' generalmente ocurren a fines de enero en el sur de Florida, desde principios hasta mediados de febrero en el centro y norte-centro de Florida, y desde mediados de febrero hasta principios de marzo en el norte y noroeste de Florida. Las ciruelas de la serie 'Gulf' tienen un período de desarrollo de la fruta entre 75 y 95 días, dependiendo del cultivar y las condiciones de crecimiento de la temporada.

\section{Recolección y manejo de frutas}

En Florida, las ciruelas se cosechan a mano desde principios de mayo hasta principios de junio. La fruta debe enfriarse lo más rápido posible después de la cosecha. Existen varias opciones para la refrigeración, incluidos los sistemas de aire forzado, la refrigeración hidráulica o el almacenamiento en cámaras frigoríficas. La fruta firme puede empaquetarse cuidadosamente a granel en una caja o colocarse en bandejas divisorias con celdas de empacado. Un árbol normalmente madurará su fruto durante un período de 10 a 15 días correspondiente con la duración de la floración y la eficiencia de los polinizadores. Los frutos de la serie 'Gulf' son firmes, pero si se recogen tarde, se 
suavizarán rápidamente. El tiempo de cosecha adecuado permite que la fruta madure en tránsito hacia los consumidores con una vida útil de 1 a 2 semanas. La recomendación para el almacenamiento postcosecha en climas templados debería aplicar para las variedades de ciruela de Florida (http://postharvest.ucdavis.edu/Commodity_Resources/ Fact_Sheets/), aunque no se han realizado estudios detallados para las variedades de ciruela de bajo enfriamiento. La temperatura óptima de almacenamiento para las ciruelas es de $30.5^{\circ} \mathrm{F}-32^{\circ} \mathrm{F}$, con una humedad relativa de $90 \%-95 \%$. Se recomienda el movimiento del aire en una habitación fría o en un refrigerador (aproximadamente 50 pies cúbicos por minuto).

\section{Rendimientos}

Se debe hacer raleo a la fruta de ciruela para permitir un tamaño de fruta satisfactorio. El rendimiento de un ciruelo maduro que se ha adelgazado en número de frutos adecuadamente será de aproximadamente 1 a 11/2 fanegas o aproximadamente 40 a 50 lbs. de fruta por árbol.

\section{Cultivares de ciruela adaptados al norte, norte-centro y noroeste de Florida}

‘Gulfbeauty' fue lanzado en 1998 y patentado por la Universidad de Florida. Su requisito de enfriamiento es de aproximadamente 225 horas. El color de la fruta es púrpura rojizo oscuro, y la carne es amarilla con un tono verde (Figura 3). La piel es agria, lo cual es común en las ciruelas japonesas, pero la carne es dulce, subácida y firme cuando está madura. La fruta es de tipo clingstone (donde la pulpa se adhiere al hueso) y se aferra al hueso incluso cuando está suave y madura. Las frutas son redondas y de tamaño mediano (13/4 pulg. de diámetro) y pesan de 55 a 70 gramos. La floración y la polinización cruzada ocurren con todas las otras ciruelas de la serie 'Gulf'. El establecimiento de frutas es bueno con flores formadas en espuelas y brotes de la temporada anterior. 'Gulfbeauty' es la primera ciruela en madurar del programa de mejoramiento de la Universidad de Florida, con un período de desarrollo de la fruta de 75 días.

La maduración ocurre aproximadamente 5 días antes de 'Gulfruby' y aproximadamente 8-12 días antes de 'Gulfblaze'. A medida que la fruta se madura por completo, su color se vuelve notablemente más oscuro (Figura 4). La fruta madura colgará en el árbol durante 7 a 10 días. La calidad es buena, especialmente para una ciruela de maduración temprana. Durante su temporada, no hay otras ciruelas frescas disponibles. Los árboles son vigorosos con tallos altos y semi-extendidos. En ausencia de condiciones de congelación, se requiere hacer un raleo para obtener un tamaño adecuado y evitar que las ramas se quiebren. Los árboles son muy resistentes al chancro bacteriano y moderadamente resistentes al escaldado de las hojas de ciruela.

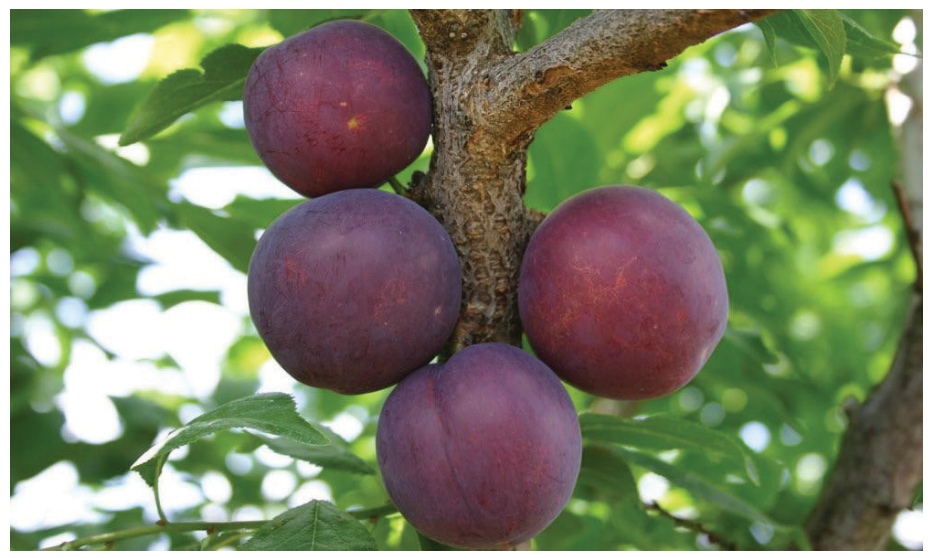

Figura 3. 'Gulfbeauty' antes de la maduración final del color. Créditos: P. Miller, UF/IFAS

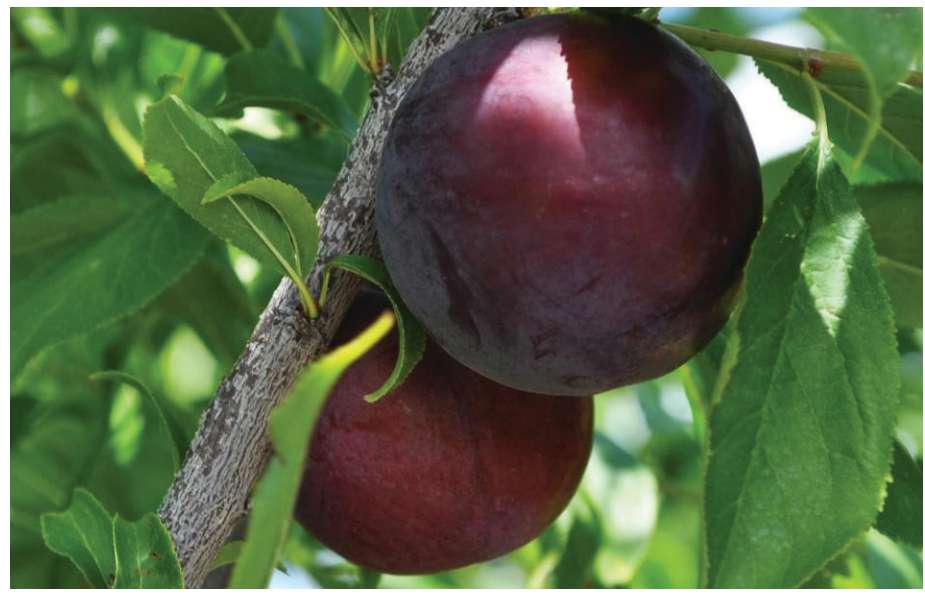

Figura 4. 'Gulfbeauty' mostrando color de maduración. Créditos: M. Olmstead, UF/IFAS

'Gulfblaze' fue lanzado y patentado por la Universidad de Florida (Figura 5). La fruta madura en medio de la temporada de ciruelas de Florida. El requisito de enfriamiento para 'Gulfblaze' es de aproximadamente 250 horas. La floración y la polinización cruzada ocurren con todas las otras ciruelas de la serie 'Gulf'. El conjunto de frutas es bueno con flores formadas en espuelas y brotes de la temporada anterior. Las frutas son muy firmes, de tamaño promedio ( $17 \%$ a 2 pulgadas de diámetro) y pesan de 70 a 80 gramos. El fruto es redondo y semi-freestone con la pulpa débilmente unida al hueso cuando madura. El color de la fruta es rojo oscuro a púrpura y la carne es naranja, dulce y subácida (Figura 6). La piel es agria, aunque la calidad general de la fruta es buena. La fruta madura de 8 a 14 días después de 'Gulfbeauty' con un período de desarrollo de la fruta de 95 días. Las características de floración, 
polinización, cuajado y maduración son las mismas que para 'Gulfbeauty'. Las hojas, los tallos y los frutos tienen una resistencia similar a la bacteriosis y a la escaldadura de las hojas de ciruela como 'Gulfbeauty'.

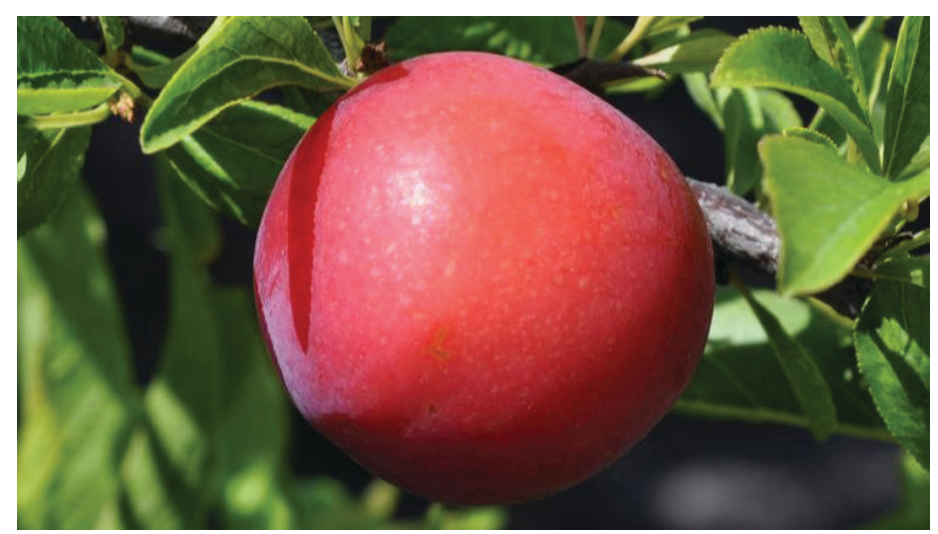

Figura 5. Fruta joven 'Gulfblaze'.

Créditos: M. Olmstead, UF/IFAS

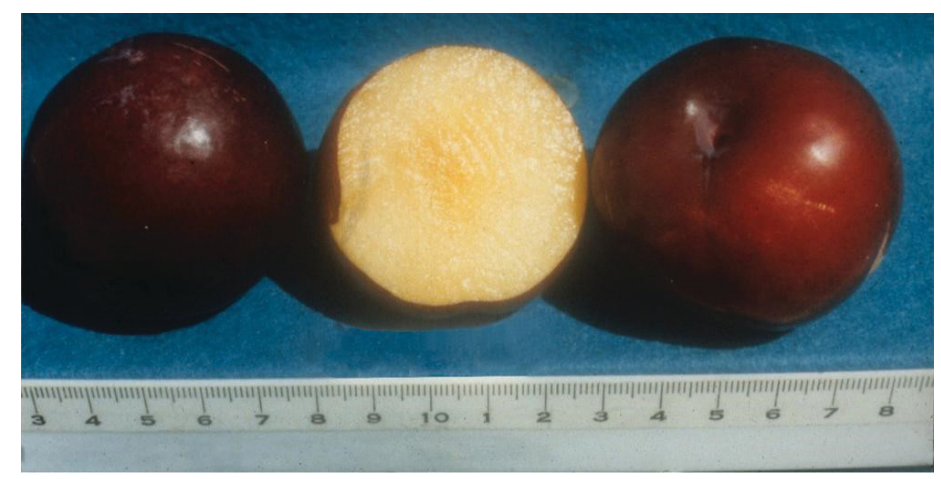

Figura 6. Fruta 'Gulfblaze' que muestra el color de la carne. Escala en centímetros.

Créditos: UF/IFAS

'Gulfrose' también está patentado por la Universidad de Florida y madura aproximadamente una semana más tarde que 'Gulfblaze', con un período de desarrollo de la fruta de 95 días (Figura 7). El requisito de enfriamiento es de aproximadamente 275 horas. Los frutos son casi redondos, semi-freestone, de tamaño promedio ( $1 \% 8$ a 2 pulgadas de diámetro) y pesan de 70 a 80 gramos. La piel es de color púrpura rojizo oscuro, y la carne es de color rojo sangre (Figura 8). La calidad de la fruta es alta con buena firmeza y vida útil. La fruta tiene una carne dulce, aromática y una piel moderadamente agria. No hay un resabio amargo común en otras ciruelas de sangre como 'Mariposa'. Las cualidades de floración, polinización, cuajado de fruta y maduración son las mismas que para las de 'Gulfbeauty'. Los árboles son moderadamente vigorosos, semi-extendidos y precoces, y producen el segundo año después de la plantación. 'Gulfrose' tiene una resistencia similar a la bacteriosis como 'Gulfbeauty'; sin embargo, es menos tolerante a la escaldadura de las hojas de ciruela que 'Gulfblaze' con una susceptibilidad similar a 'Gulfgold', lo que limita la longevidad de los árboles.

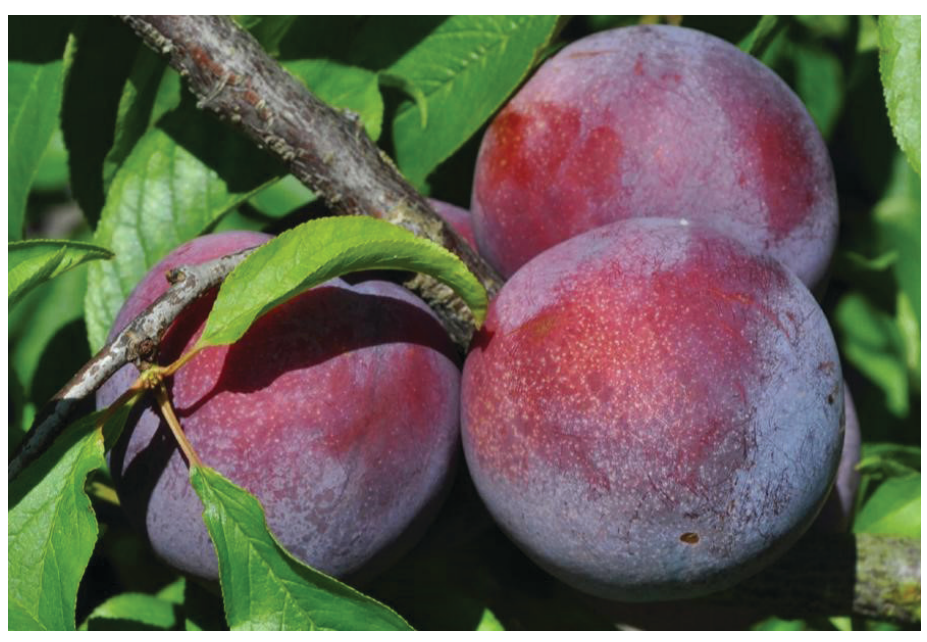

Figura 7. Fruta joven 'Gulfrose'.

Créditos: M. Olmstead, UF/IFAS

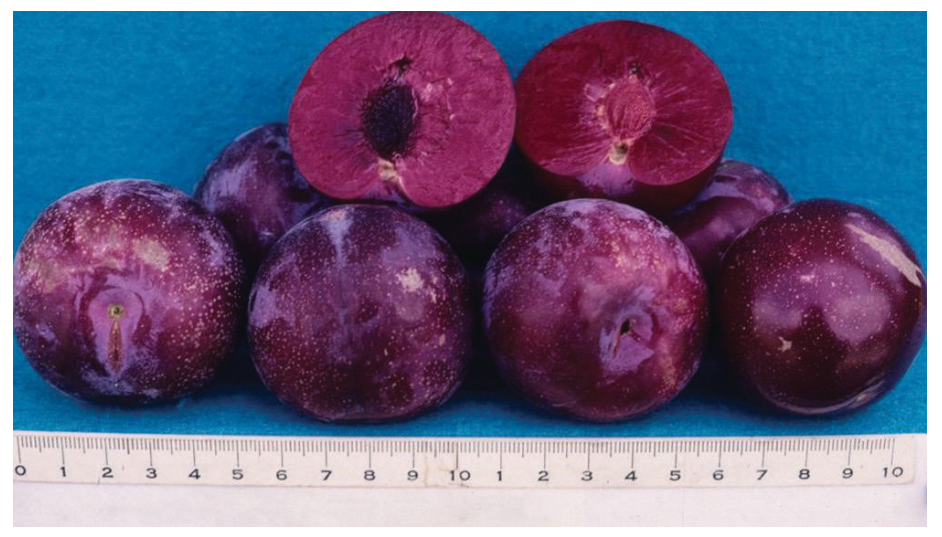

Figura 8. Fruto 'Gulfrose' que muestra el color de la pulpa y la piedra de hueso.

Créditos: UF/IFAS

'Gulfruby' se originó en el programa de fitomejoramiento de la Universidad de Florida, pero no fue lanzado por la universidad debido a su susceptibilidad a la bacteriosis. Fue propagado por primera vez junto con 'Gulfgold' en 1982 por el vivero de Grand Island en Umatilla, Florida. No está patentado, por lo tanto, es una variedad pública. La bacteriosis ocurre fácilmente en las hojas y ramitas de 'Gulfruby' y se ve agravado por las frecuentes lluvias de verano. En general, el árbol puede sobrevivir de 5 a 8 años y proporcionar varios cultivos de ciruelas de maduración temprana. Las frutas son de tamaño mediano, de hasta 2 pulgadas de diámetro y tienen forma redonda (Figura 9). La carne es dulce, de color amarillo con un tinte verdoso, y se adhiere a la semilla pequeña en la madurez cuando el fruto es suave. El color de la piel es rojo a púrpura con características agrias. La fruta colgará en el árbol de 3 a 5 días después de que se desarrolle el color rojo completo de la piel y madurará de 7 a 10 días antes de 'Gulfblaze.' El árbol no es tan vigoroso ni posee tantas de las fuertes tendencias de tiro vertical de 'Gulfbeauty'. 'Gulfruby' tiene más problemas con la bacteriosis que los otros cultivares de bajo enfriamiento recomendados para ensayar. La 
enfermedad puede causar chancros en la madera y daños significativos en las hojas conduciendo a la defoliación, lo que puede provocar quemaduras solares en la fruta debido a la pérdida de hojas.

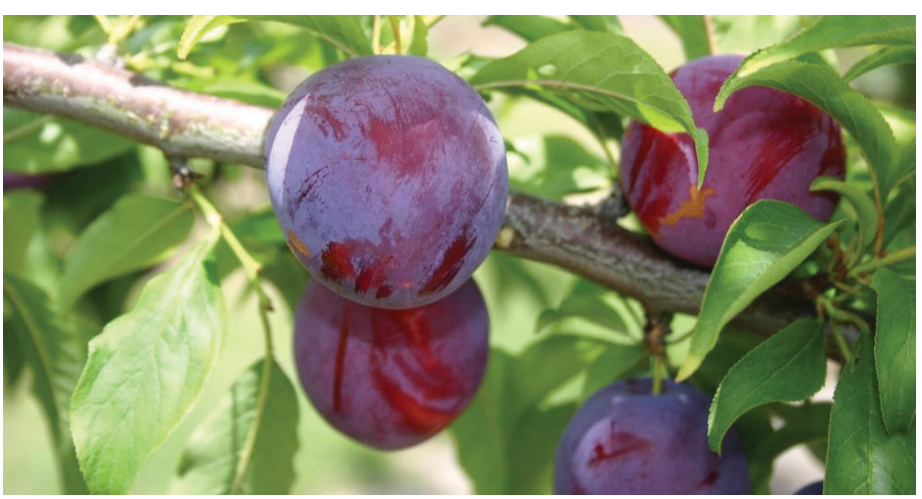

Figura 9. Fruta 'Gulfruby'.

Créditos: P. Miller, UF/IFAS

'Gulfgold' es una ciruela de piel amarilla, pero desarrolla un rubor rojo a medida que avanza la maduración. La carne de la fruta es amarilla y semiblanda cuando está madura. Aunque desarrollado por la Universidad de Florida, no fue patentado. La fruta madura a fines de mayo hasta mediados de junio. Son las más dulces de la serie 'Gulf'. 'Gulfgold' es susceptible al escaldado de las hojas, lo que generalmente limita la vida de los árboles en Florida. El hábito de crecimiento de los árboles es achicado. La floración ocurre unos días luego que 'Gulfruby'. 'Gulfgold' se poliniza de forma cruzada con las otras ciruelas 'Gulf'.

\section{Cultivares de ciruela}

\section{condicionalmente recomendados} para ensayos en el norte de Florida debido a un mayor requisito de enfriamiento

Los cultivares de ciruela con el prefijo $A u$ se han lanzado del programa de mejoramiento de ciruela de la Universidad de Auburn y 'Robusto', 'Segundo' y 'Byrongold' provienen del programa de mejoramiento de fruta de hueso del USDA-ARS en Byron, GA. Pueden polinizarse entre sí. Los viveros de Florida pueden vender otras variedades como 'Scarlet Beauty'; sin embargo, no hay datos disponibles sobre las características de los árboles o sobre la producción frutal.

'Au-Homeside' produce una ciruela de color rojo claro con carne de color ámbar. El tamaño del fruto es ovalado y de aproximadamente $2 \frac{1}{3} 3$ pulgadas de diámetro. La fruta es atractiva y la calidad general es buena. La fruta madura a mediados de junio, y tiende a alcanzar su tamaño antes de madurar el color. Los árboles no son vigorosos, pero 'Au-Homeside' es tolerante a la escaldadura de las hojas del ciruelo.

'Au-Producer' tiene la piel de color rojo oscuro y la carne también es roja. El tamaño del fruto es pequeño, redondo y de menos de 2 pulgadas de diámetro. La calidad de la fruta es alta y la fruta madura a mediados de junio. El vigor de los árboles es moderado, pero los árboles requieren un fuerte raleo de la fruta. 'Au-Producer' es tolerante a la escaldadura de las hojas del ciruelo. El requisito de enfriamiento es de aproximadamente 750 unidades.

'Au-Roadside' produce una fruta magenta con un color rojo carne. El tamaño de la fruta tiene menos de 2 pulgadas de diámetro y tiene forma ovalada. La calidad de la fruta es muy buena y la fruta madura a mediados de junio. Los árboles son muy vigorosos. La fruta tiende a ser demasiado blanda para el envío comercial. 'Au-Roadside' es tolerante al escaldado de hojas de ciruela. El requisito de enfriamiento es de aproximadamente 750 unidades.

'Au-Rosa' produce frutos rojos con algunas áreas amarillas claras. El tamaño de la fruta es de 2 pulgadas de diámetro y forma redonda. La calidad de la fruta es buena y la fruta es atractiva. La fruta madura a mediados de junio. 'Au-Rosa' es resistente al escaldado de hojas del ciruelo. El requisito de enfriamiento es de aproximadamente 750 unidades.

El color de la piel de 'Au-Rubrum' es marrón y el color de la carne es rojo. El tamaño de la fruta es de 2 pulgadas de diámetro y forma redonda. La fecha de maduración es a mediados de junio. El vigor del árbol es bueno.

'Au-Rubrum' es tolerante al escaldado de hojas de ciruela. El requisito de enfriamiento es de aproximadamente 750 unidades.

'Byrongold' produce una fruta con piel y pulpa amarillas. La fruta desarrolla un rubor rojo durante la última parte de la maduración. Las frutas son redondas y de aproximadamente 2 pulgadas de diámetro. La fruta madura desde fines de junio hasta principios de julio con buena firmeza y calidad de fruta. Los árboles son muy vigorosos, pero pueden tener algunos problemas con la escaldadura de las hojas. El requisito de enfriamiento es de aproximadamente 450 unidades.

'Excelsior' es una ciruela nativa descubierta por George Tabor del vivero de Glen St. Mary y requiere aproximadamente 400 horas de frío. Tanto la carne como la fruta son amarillas. El tamaño de la fruta es de aproximadamente 2 pulgadas. La carne es algo translúcida y acuosa. 
'Methley' es una variedad antigua que ya no se recomienda debido al pequeño tamaño del fruto, la falta de firmeza y a la susceptibilidad al escaldado de las hojas del ciruelo y otras enfermedades de origen bacteriano. Es autopolinizante. El requisito de enfriamiento es de aproximadamente 650 unidades.

'Robusto' produce una fruta roja con pulpa amarilla y madura a principios de junio. El árbol florece a principios de marzo y requiere aproximadamente de 400 a 500 unidades de frío.

'Santa Rosa' produce una fruta de color púrpura/rojo con pulpa roja. Santa Rosa es un cultivar más antiguo que ya no se recomienda debido a la susceptibilidad al escaldado de la hoja del ciruelo y otras enfermedades de origen bacteriano. El requisito de enfriamiento es de aproximadamente 650 unidades.

'Segundo' es una ciruela roja con pulpa amarilla que madura a mediados o finales de junio. La fruta es algo blanda y el árbol requiere aproximadamente de 400 a 500 unidades de frío.

\section{Establecimiento del huerto}

Las ciruelas, como todos los árboles frutales, deben plantarse a pleno sol. El mejor suelo y lugar para el cultivo de ciruelas es un limo arenoso bien drenado ubicado en las cimas de las colinas con un buen drenaje de aire para la protección contra la congelación de primavera. Si el sitio tiene un drenaje deficiente, se deben hacer ajustes para mejorar el drenaje antes del establecimiento del huerto, ya que los ciruelos no toleran períodos prolongados de inundación. Los portainjertos de durazno 'Flordaguard' o 'Nemaguard' o los portainjertos de ciruela/híbridos de ciruela como 'Sharpe' deben usarse para reducir el impacto de los nematodos, particularmente el nematodo agallador del durazno (Meloidogyne floridensis), que se encuentra solo en Florida. El uso de portainjertos resistentes a los nematodos es más crítico en suelos arenosos. Los suelos fértiles ricos en materia orgánica son preferibles a los suelos no fértiles para reducir las poblaciones de nematodos.

El establecimiento de huertos para ciruelas es similar al de duraznos y nectarinas. Los ciruelos se deben plantar con 12 $\times 18$ pies o $15 \times 20$ pies dentro y entre hileras, lo que resulta en 201 a 145 árboles por acre, respectivamente. Se puede usar un espacio más estrecho de 12 pies entre hileras, pero puede ser difícil de mantener una vez que los árboles han alcanzado su tamaño completo.
Se debe realizar una prueba de suelo para hacer ajustes antes del establecimiento y anualmente. Las ciruelas crecen bien cuando el pH del suelo está en un rango de 5.5 a 6.5 . Los resultados de las pruebas de suelo proporcionarán recomendaciones para la adición de cal o azufre en función del pH ideal. Es más eficiente aplicar cal o azufre al suelo después de que se hayan eliminado las malezas o pastos alrededor del árbol.

A fines del verano o a principios del otoño antes del establecimiento del huerto, las malezas en la hilera de siembra pueden eliminarse manualmente o utilizando herbicidas. Si aplica herbicidas, no labre el suelo hasta que las malezas hayan muerto. Labrar las franjas en hileras también facilitará la plantación de árboles, el control temprano de malezas y el crecimiento inicial de los árboles. Para obtener más información, consulte https://edis.ifas.ufl.edu/wg023.

Plante árboles de raíz desnuda en diciembre o enero a la misma profundidad en que se cultivaron en el vivero. Todas las raíces deben estar cubiertas por tierra. Los árboles crecidos en contenedores se pueden plantar en cualquier momento durante el año, pero si las raíces se han adherido a las macetas, es mejor plantarlas cuando están inactivas para facilitar el desarrollo de las raíces antes que salgan las hojas. Riegue los árboles a fondo en la siembra.

Durante el primer año después del establecimiento, las cuatro consideraciones principales son irrigación, control de malezas, fertilización y daños por conejos o venados. En la mayoría de los lugares, el riego es esencial. El control de malezas es crítico, ya sea por métodos manuales o por el uso de herbicidas de pre y postemergencia. Para las plantaciones de propietarios de viviendas, los métodos manuales de control de malezas pueden ser satisfactorios, mientras que los herbicidas pueden ser el método de elección para las plantaciones medianas a grandes. Si los herbicidas son el método de elección, es posible que tengan que aplicarse durante todo el año. Inicialmente, una hilera libre de malezas de aproximadamente 3 pies de ancho es satisfactoria. Debería expandirse a 5 pies después de unos años a medida que los árboles crecen.

\section{Formación, poda y raleo de frutas}

Formación se refiere al proceso de dar forma al marco básico del árbol, mientras que la poda se refiere a la eliminación de brotes y ramas para promover la productividad continua del árbol (https://edis.ifas.ufl.edu/hs365). Al plantar un árbol de raíz desnuda, la formación comienza el primer año eliminando al menos $1 / 3$ de la parte superior ('rebajado') para equilibrar el crecimiento de los brotes con 
el crecimiento del sistema de raíces. Idealmente, los árboles deben tener una altura de $2 \frac{1}{2}$ a 3 pies después del rebrote. La mayoría de los brotes se activarán dentro de 1 pie de la parte superior. Retire todos los brotes de menos de 18 pulgadas de altura. En general, de 3 a 5 brotes son igualmente distanciados alrededor del tronco para formar las extremidades del andamio (brazos o ramas madre). Se debe alentar a los brotes a crecer en un ángulo amplio $\left(>45^{\circ}\right)$ desde el tronco para formar un marco fuerte. Las ramas del andamio y los brotes vigorosos se pueden recortar o retirar si el centro del árbol se llena. Durante el segundo año y años posteriores, se desarrollarán extremidades secundarias a partir de las 4 a 6 extremidades principales del andamio.

El crecimiento vigoroso de los brotes cada año requiere una poda anual. La mayor parte de la poda se realiza durante la latencia (diciembre a febrero). Durante los primeros años, se puede retener más crecimiento nuevo que en años posteriores cuando los árboles se acercan a su tamaño deseado. La poda controla la altura del árbol, elimina las ramas que se cruzan o se enredan, y permite que la luz adecuada penetre en el interior. Las ciruelas se pueden entrenar con un sistema de líder central, como con una manzana, o con múltiples líderes que se extienden para limitar la altura del árbol. Los árboles maduros son descabezados, lo que limita su altura a alrededor de 8 pies, por lo que la fruta se puede recoger sin el uso de escaleras. La poda de verano en junio después de la cosecha de fruta sigue los mismos objetivos, pero se elimina menos madera, y el adelgazamiento de los interiores de los árboles es el foco de este tiempo de poda. Muchos cultivares de ciruela dan fruto en brotes largos ('látigos'). Estos látigos se reducen a 1-3 pies para limitar la carga de fruta y evitar que las ramas se quiebren. Además de formar frutos en los látigos, los árboles más viejos ponen frutos en espuelas de 2 a 4 pies, por lo que algunos de estos pueden eliminarse para limitar la carga de cultivo (Figura 10, Figura 11). La poda debe usarse para reducir la cantidad de raleo de la fruta que sería necesaria. Retrasar la poda a fines del invierno y principios de la primavera durante el período de heladas retrasa la floración y puede ayudar a garantizar que se establezca una carga de cultivo suficiente.

Una de las actividades más importantes en la producción de fruta de hueso es reducir la carga de la cosecha para desarrollar el tamaño de fruta comercializable. La fruta se retira a mano, aproximadamente un mes después de la floración, cuando la fruta tiene un diámetro de $1 / 4$ a $1 / 2$ pulgada. El raleo efectivo para mejorar el tamaño de la fruta se debe hacer antes del endurecimiento del hueso, de lo contrario los esfuerzos de raleo no aumentan el tamaño de la fruta. La fruta puede estar sujeta a 'caída tardía', a veces llamada 'caída de junio' en los climas del norte, lo que da como resultado que el árbol aborte la fruta. Esto ocurre debido a una polinización incompleta y, por lo tanto, no se forman semillas.

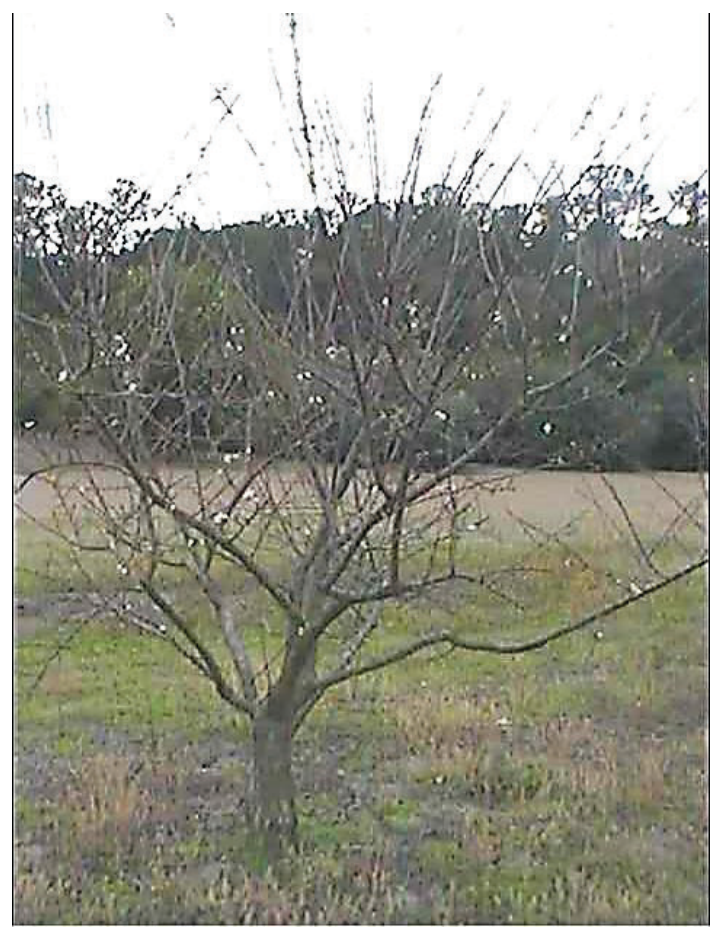

Figura 10. Árbol sin podar que muestra el centro desordenado, la altura sin restricciones y ramas bajas.

Créditos: P. Miller, UF/IFAS

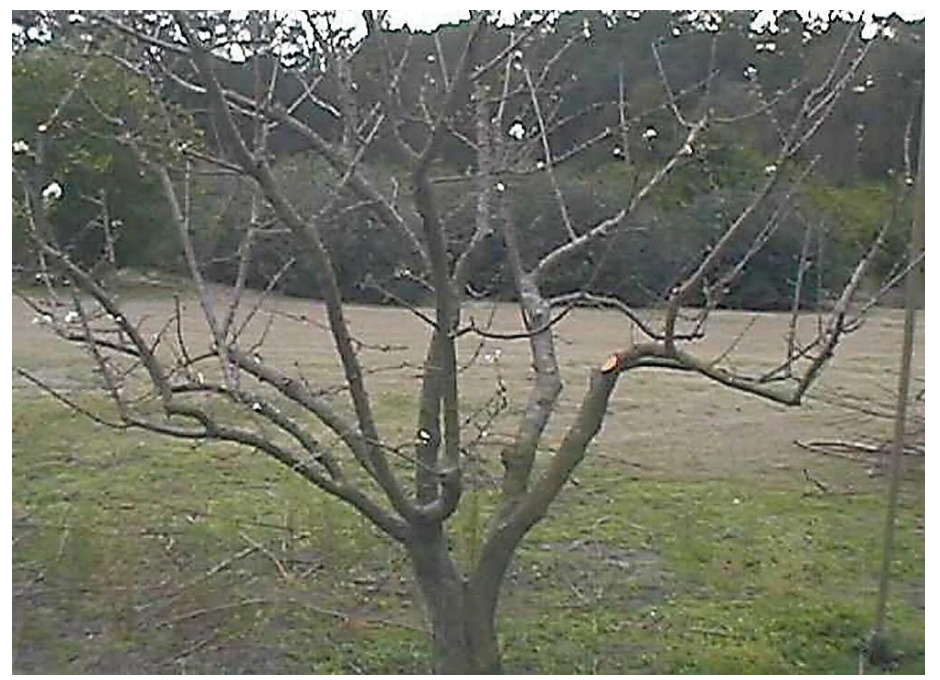

Figura 11. Árbol podado con algunas extremidades centrales eliminadas, altura reducida y extremidades inferiores eliminadas. Créditos: P. Miller, UF/IFAS

Idealmente, la fruta debe estar separada de 3 a 6 pulgadas. Si el cultivo es ligero, solo se debe retirar el exceso de fruta de grupos pesados. Dado que las ciruelas tienen un largo período de floración y múltiples oleadas de frutos, el raleo se debe hacer varias veces. El raleo no debe iniciarse hasta que haya pasado el peligro de temperaturas de congelación a fines del invierno/principios de la primavera. 


\section{Protección contra congelamiento}

Durante la latencia invernal, antes de la activación de los brotes, rara vez se producen daños por congelación en los ciruelos en Florida porque las temperaturas mínimas deben caer por debajo de $5^{\circ} \mathrm{F}$ para que se produzcan lesiones. Sin embargo, el daño a los cultivos puede ocurrir a fines del invierno cuando las flores están expuestas a temperaturas bajo cero $\left(<32^{\circ} \mathrm{F}\right)$. El escenario más probable para este daño es después del paso de un frente frío, ya sea un evento advectivo o porun evento de congelación de radiación. Se produce una congelación advectiva en condiciones de viento y frío, mientras que un cielo nocturno claro y tranquilo permite que la radiación de calor de la superficie de la tierra a la atmósfera induzca una congelación de radiación. La temperatura mínima crítica que un brote de flor puede tolerar depende de la etapa de su desarrollo. Durante la oleada de brotación, los botones florales pueden tolerar $25^{\circ} \mathrm{F}$ sin daño. Sin embargo, después de que las flores se han abierto y/o la fruta se ha formado, solo pueden tolerar $28^{\circ} \mathrm{F}-30^{\circ} \mathrm{F}$. Incluso a estas temperaturas puede ocurrir daño dependiendo de la duración de la exposición.

Para protegerse de las temperaturas bajo cero, los árboles pueden cubrirse con una lona u otro material. Sin embargo, las cubiertas por sí solas no protegen adecuadamente los brotes de fruta del daño, por lo que se debe utilizar una fuente de calor. El agua de los aspersores utilizados para el riego proporcionará una excelente fuente de calor. Este calor y niebla atrapados proporcionarán protección contra temperaturas muy bajas. También se pueden usar fuentes de calor eléctricas, como bombillas colocadas debajo de la lona.

Otro método de protección contra el frío es el riego por aspersión (Figura 12). Cuando el agua se congela, libera calor al objeto con el que está en contacto mientras pasa de una fase líquida a una sólida. Durante muchas heladas de Florida, se puede aplicar suficiente agua a través de los sistemas de riego aéreos para proteger las flores y las frutas jóvenes de las lesiones por congelamiento. Solo se logrará una protección significativa si los botones florales están en contacto con el rocío de agua continuamente. El agua debe aplicarse continuamente hasta que el hielo se derrita al día siguiente o la temperatura del bulbo húmedo supere los $32^{\circ} \mathrm{F}$. Ramas pueden quebrarse como resultado del peso del hielo.

La tasa de aplicación de agua y la cobertura son críticas para la protección contra congelamiento. Algunos factores que afectan la tasa de aplicación de agua incluyen temperatura, humedad relativa y velocidad del viento. En general, el volumen de agua debe ser de al menos $1 / 3$ pulg. por hora para velocidades de viento inferiores a $10 \mathrm{mph}$. Si no se aplica suficiente agua, o los rociadores no proporcionan una cobertura adecuada, entonces la cantidad de daño por congelamiento puede ser mayor que si no se hubiera aplicado agua. Las desventajas de controlar la congelación con riego incluyen el rompimiento de las ramas del andamio (Figura 12) y de los brotes con el peso del hielo, el uso de una gran cantidad de agua aplicada al área y la inversión en grandes pozos de agua y en combustible (diésel), que es más confiable que la energía eléctrica. Se puede encontrar una discusión más exhaustiva sobre la protección contra congelamiento en Protecting Blueberries from Freezes in Florida en https://edis.ifas.ufl.edu/hs216.

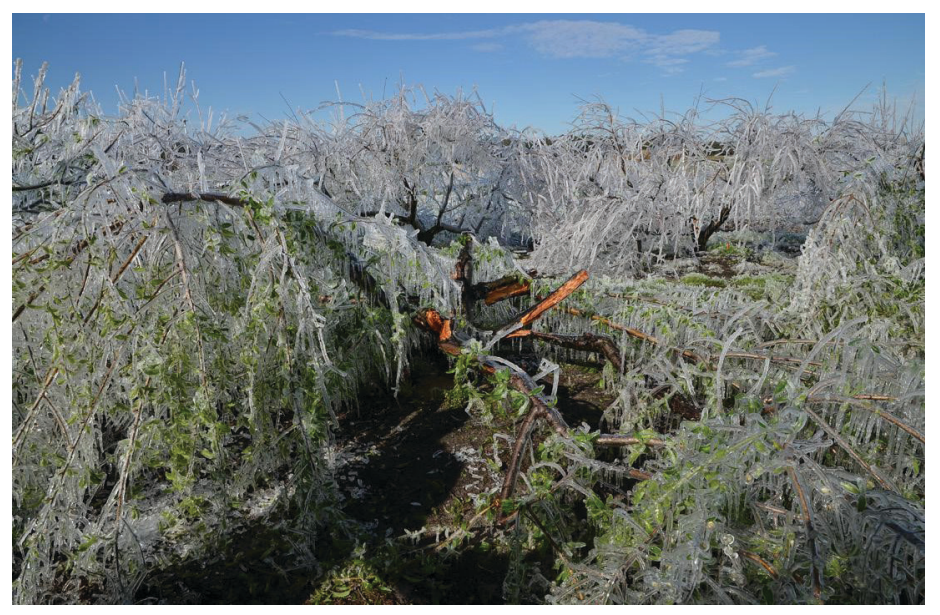

Figura 12. Protección contra congelamiento con riego por aspersión, que muestra las ramas dobladas y divididas por el peso del hielo. Créditos: M. Olmstead, UF/IFAS

\section{Riego}

El riego es necesario durante el establecimiento del huerto y es importante para proporcionar humedad durante los períodos secos de la temporada de crecimiento. Se puede usar riego por goteo, aspersor tipo microjet o por aspersión aérea, cada uno de los cuales tiene ventajas y desventajas. El riego por goteo utiliza la menor cantidad de agua y no humedece el follaje. En los suelos arcillosos del norte de Florida y el panhandle, el agua que sale de un emisor de goteo se extenderá lateralmente para cubrir la zona de la raíz. Sin embargo, en suelos arenosos, una sola línea de goteo en la hilera no humedecerá toda la zona de la raíz debido al movimiento vertical del agua. Los aspersores microjet son similares al riego por goteo, pero proporcionan una mejor cobertura de la zona de la raíz. Ambos métodos de bajo volumen requieren mantenimiento para eliminar partículas y/o precipitados que obstruyen los emisores de agua. El riego por aspersión aérea permitirá el riego entre las hileras del cultivo y es más fácil detectar boquillas obstruidas con este sistema. También sirve como sistema de protección contra congelamiento. 
Para las plantaciones de dueños de casa, el riego manual es satisfactorio. Irrigar dos veces por semana con 2 galones para un árbol pequeño y hasta 8 galones para un árbol grande es generalmente satisfactorio.

\section{Fertilización}

No aplique fertilizante sintético en el momento de la siembra, a menos que se necesite cal para aumentar el $\mathrm{pH}$ del suelo o se necesite azufre para disminuir el pH del suelo según los resultados iniciales de la prueba del suelo. La fertilización debe ser ligera durante el primer año. En general, múltiples aplicaciones reducirán el potencial de lixiviación de nutrientes.

En Florida, el fósforo generalmente está disponible en cantidades suficientes en el suelo y no se necesita en cantidades tan grandes como el nitrógeno o el potasio. La reducción de las aplicaciones de fósforo puede ayudar a reducir la lixiviación y minimizar el impacto ambiental por el exceso de aplicaciones. Disperse de $1 / 2$ a $1 \mathrm{lb}$ de 10-2-10 $\left(\mathrm{N}-\mathrm{P}_{2} \mathrm{O}_{5}-\mathrm{K}_{2} \mathrm{O}\right)$ de manera uniforme en un área de 2 a 5 pies alrededor de cada árbol. Los micronutrientes se pueden suministrar usando un 10-2-10 con micronutrientes.

Los ciruelos deben fertilizarse cada 6 semanas desde el 1 de marzo hasta el 31 de agosto con 4 oz. de 10-10-10 por aplicación durante el primer año. En el segundo año, la cantidad se puede aumentar a $8 \mathrm{oz}$. por aplicación. A partir del tercer año en adelante, la cantidad por aplicación se puede aumentar a 1 libra por cada aplicación.

Dependiendo de los niveles de fertilidad de la hoja y el suelo, el 10-10-10 puede sustituir el nitrato de amonio o el nitrato de calcio. Sin embargo, la cantidad de nitrógeno aplicado debe permanecer casi igual independientemente del producto seleccionado. Por ejemplo, 10-10-10 contiene $10 \%$ de nitrógeno mientras que nitrato de amonio contiene $35 \%$ de nitrógeno. Por lo tanto, se necesitan aproximadamente 3 unidades de 10-10-10 para igualar una unidad de nitrato de amonio. La elección del 10-10-10, con micronutrientes o cualquier otro fertilizante o combinación de fertilizantes, puede basarse en los niveles de nutrientes en la hoja. Los niveles óptimos de nutrientes en la hoja se presentan en la Tabla 1. Los niveles de nutrientes en la hoja que están por debajo del rango óptimo son deficientes y los niveles por encima del rango óptimo son excesivos.
Tabla 1. Niveles óptimos de nutrientes foliares de ciruelo a partir de hojas recolectadas a mediados del verano de espuelas no fructíferas. (Jones et al. 1991).

\begin{tabular}{|l|c|c|}
\hline \multicolumn{1}{|c|}{ Elemento } & Símbolo & Rango óptimo \\
\hline Nitrógeno & $(\mathrm{N})$ & $2.4-3.0 \%$ \\
\hline Fósforo & $(\mathrm{P})$ & $0.14-0.25 \%$ \\
\hline Potasio & $(\mathrm{K})$ & $1.6-3.0 \%$ \\
\hline Calcio & $(\mathrm{Ca})$ & $1.0-1.5 \%$ \\
\hline Magnesio & $(\mathrm{Mg})$ & $0.3-0.8 \%$ \\
\hline Boro & $(\mathrm{B})$ & $25-60 \mathrm{ppm}$ \\
\hline Hierro & $(\mathrm{Fe})$ & $100-250 \mathrm{ppm}$ \\
\hline Zinc & $(\mathrm{Zn})$ & $20-5 \mathrm{ppm}$ \\
\hline Cobre & $(\mathrm{Cu})$ & $6-16 \mathrm{ppm}$ \\
\hline Manganeso & $(\mathrm{Mn})$ & $40-160 \mathrm{ppm}$ \\
\hline Molibdeno & $(\mathrm{Mo})$ & $20-200 \mathrm{ppm}$ \\
\hline Producción orgánica y de baja \\
\hline aplicación de pesticidas en Florida
\end{tabular}

La producción orgánica en Florida no se ha practicado ampliamente, por lo que hay poca información al respecto. Hay muy pocas operaciones comerciales de ciruela orgánica en los Estados Unidos debido a enfermedades e insectos que son difíciles de controlar con opciones orgánicas. Sin embargo, se puede encontrar una guía para la producción de ciruelas orgánicas y de baja aplicación en el sitio web del Programa Nacional de Asistencia para la Agricultura Sostenible (AT-TRA por sus siglas en inglés): https://attra. ncat.org/attra-pub-summaries/?pub $=442$.

\section{Insectos}

Los insectos que son de mayor preocupación para los productores de ciruelas son el curculio de ciruela, las chinches, la escama de San José o la escama blanca del durazno, los ácaros y los barrenadores (común y pequeño) de los duraznos. La biología del insecto, el tiempo y el método de aplicación, son importantes para prevenir el daño a la fruta.

El curculio del ciruelo es un gorgojo que emerge del suelo durante la primera parte del desarrollo del fruto (Figura 13). En general, el curculio del ciruelo tiene el potencial de eliminar todo el cultivo de ciruelas. La hembra hará un corte en la pequeña fruta de ciruela y depositará un huevo en la carne. El corte tiene forma de media luna y se cura, formando una cicatriz de color marrón claro en 12 horas (Figura 14). El huevo sale del cascarón rápidamente y el pequeño gusano blanquecino se hace camino comiéndose la carne hasta que alcanza la semilla de la fruta. Si la semilla o hueso no se ha endurecido y continua blando, el gusano 
ingresará al material gelatinoso del embrión de la semilla y se alimentará (Figura 15). La ciruela pequeña se volverá rojiza y caerá del árbol. Si el gusano no alcanza la semilla antes del endurecimiento del hueso, formará un túnel alrededor de este y luego emergerá. El túnel almacenara el excremento de color marrón y la lesión aumentará las posibilidades de que la fruta madure prematuramente y se pudra. Cuando el gusano sale de la fruta, se convertirá en pupa en el suelo y emergerá como adulto en tan solo 60 días y continuará el ciclo. Los gusanos de las generaciones futuras pueden continuar el ciclo en la fruta cosechada y volverla inservible (Figura 16).

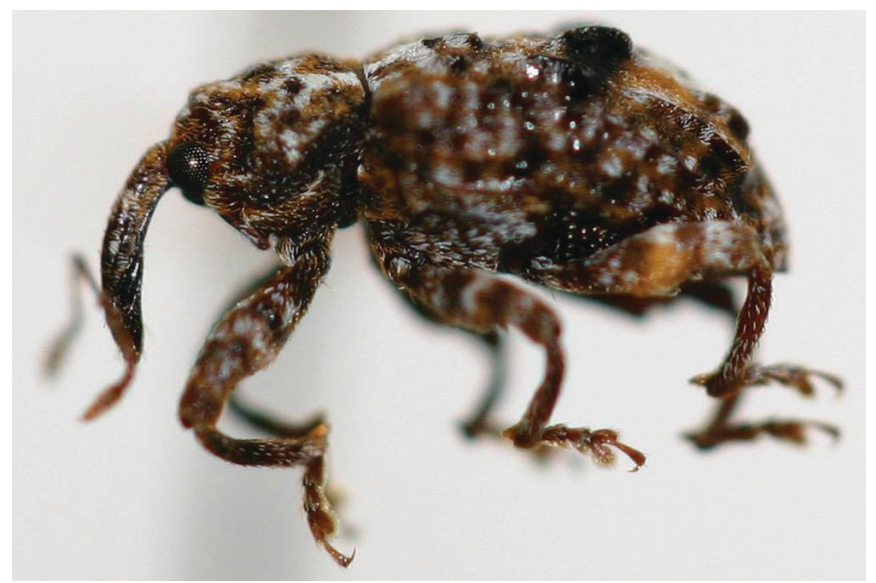

Figura 13. Hembra adulta del curculio de ciruela.

Créditos: P. Miller, UF/IFAS

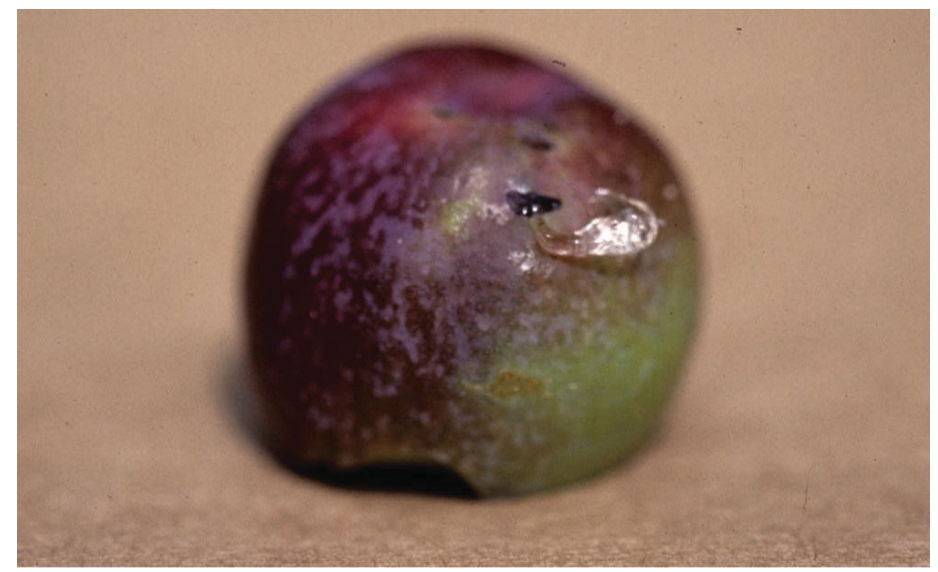

Figura 14. Corte de media luna en frutos caídos con gomosis.

Créditos: P. Miller, UF/IFAS

Las aspersiones de insecticidas deben aplicarse cuando los adultos emergen del suelo. Las recomendaciones de aspersión se pueden encontrar en Insect Management in Peaches en https://edis.ifas.ufl.edu/ig075.pdf o en Southeastern Peach, Nectarine and Plum Pest Management and Culture Guide (Guía de cultivo y manejo de plagas de durazno, nectarina y ciruela del sureste - https://secure.caes.uga.edu/ extension/publications/files/pdf/B\%201171_12.PDF). El monitoreo de las poblaciones se puede hacer con trampas de Tedder colocadas en el huerto. Eventos naturales, como la separación de la cáscara, cuando los sépalos y los pétalos son empujados por la fruta en crecimiento, también puede usarse para indicar que las hembras están presentes y están comenzando a poner huevos. En ciruelas silvestres, las poblaciones de curculio del ciruelo están presentes y siguen un ciclo natural. La separación de la cáscara generalmente coincide con la aparición del curculio, por lo que observar las ciruelas silvestres durante el inicio de este evento, puede ayudar a cronometrar las aplicaciones de insecticidas.

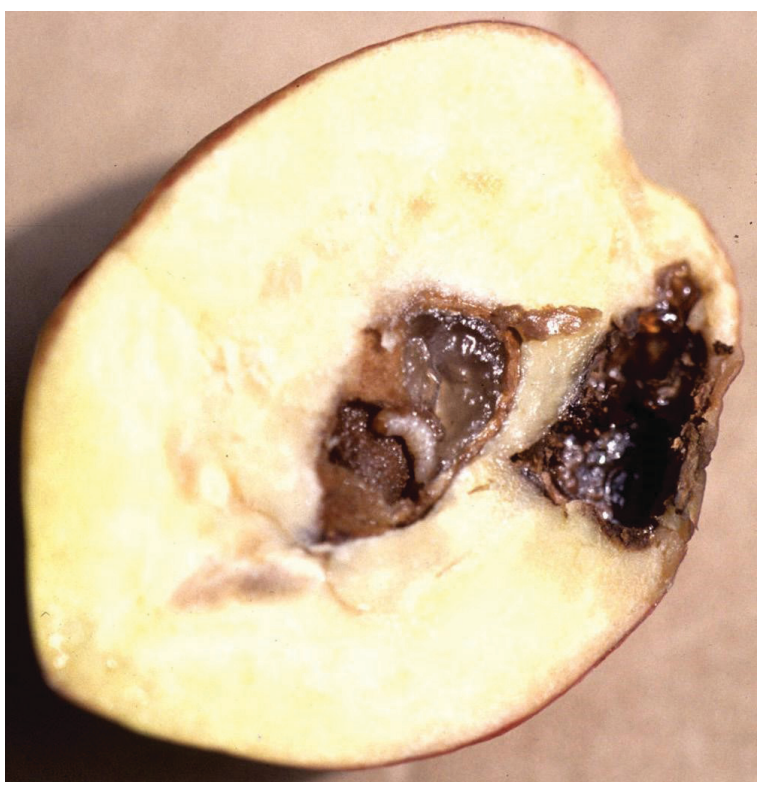

Figura 15. Larvas de curculio comiendo el embrión. Pudrición en el punto de entrada, con gomosis.

Créditos: P. Miller, UF/IFAS

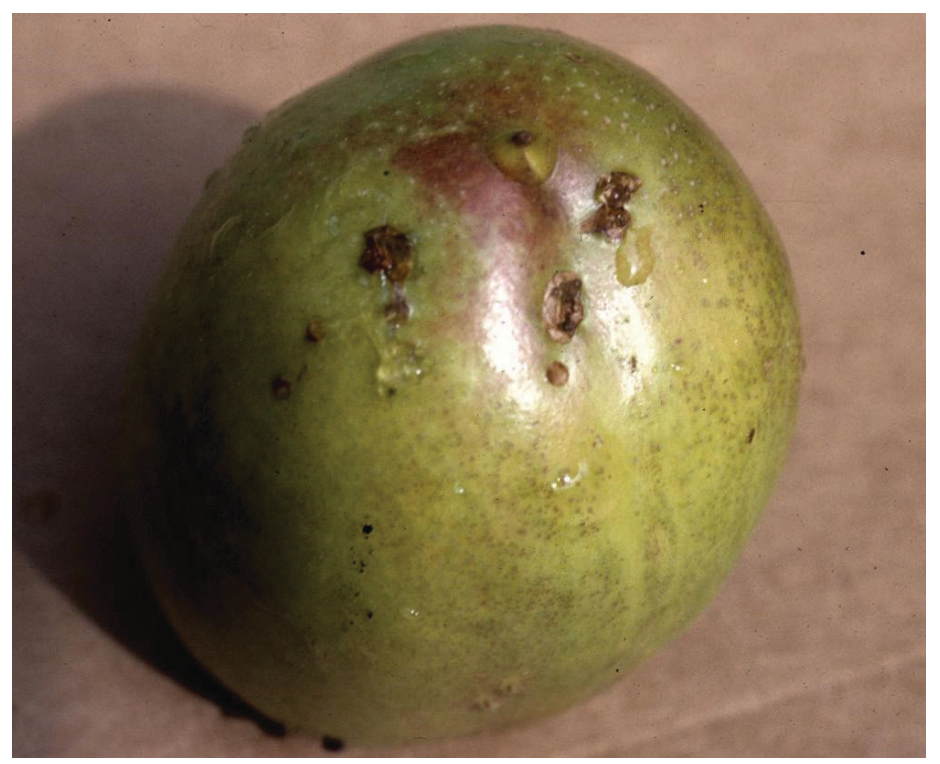

Figura 16. Múltiples cortes para la puesta de huevos.

Créditos: P. Miller, UF/IFAS

Si el curculio ha comido porciones a lo largo de los bordes de las hojas de ciruela o áreas de la fruta pequeña, esto puede ser otro indicador de la aparición de adultos del curculio de ciruela. Los insectos generalmente comienzan 
a alimentarse unos días antes de poner huevos. En general, la hembra comenzará a cortar la fruta que se encuentra hacia el exterior del dosel y cortará cada fruta sucesiva que baja por la rama hacia el interior del árbol. A menudo, sus primeros intentos de colocación no formarán una larva dentro de la fruta, y el cultivo puede protegerse adecuadamente con un insecticida a la primera señal de corte. Es posible ver los gorgojos de curculio en el árbol. Tienen aproximadamente $4 \mathrm{~mm}$ de longitud y un hocico largo. Los vientos moderados los expulsarán del árbol para que sean más fáciles de detectar en la mañana o en la noche. No son fáciles de encontrar y se moverán para evitar ser vistos. Un buen método para observar el insecto es colocar una sábana blanca debajo del árbol y agitar las ramas. Los gorgojos caerán y se pueden ver en el fondo blanco.

Los métodos de control y las recomendaciones actuales se pueden obtener en la Oficina de Extensión de su Condado o en la Guía de cultivo y manejo de plagas de durazno, nectarina y ciruela del sureste (https://secure.caes.uga.edu/ extension/publications/files/pdf/B\%201171_12.PDF).

La escama de San José es un insecto perforador y chupador en la corteza de los árboles que puede ser devastador si las poblaciones establecen una colonia. Después de la eclosión, la hembra sondea a través de la corteza y aspira agua y carbohidratos del árbol. Aproximadamente una semana después de la unión a la corteza, se desarrolla un recubrimiento ceroso y las escamas se vuelven difíciles de matar con insecticidas. La eclosión no ocurre de una vez, lo que limita aún más la efectividad del insecticida.

La escama de San José aparece como manchas cerosas grisáceas en la corteza del árbol. A diferencia de la escama blanca del durazno que es más grande y se puede ver fácilmente a fines del verano debido a sus poblaciones masculinas blancas como la nieve, la escama de San José no es fácil de ver. Sin embargo, las poblaciones se pueden confirmar cortando un pequeño trozo de corteza en la capa cambial y observando puntos morados en la rama donde la hembra se ha estado alimentando (Figura 17).

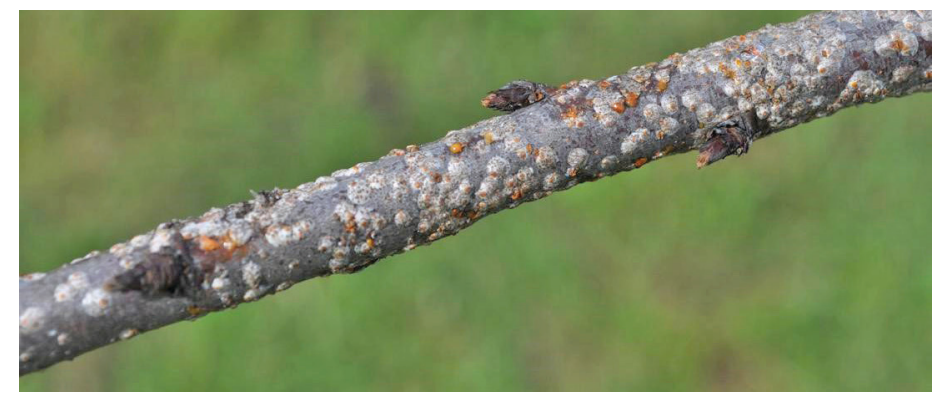

Figura 17. Escama de San José sobre la corteza con coloración roja en donde la hembra ha sondeado y se está alimentando del cambium. Créditos: M. Olmstead, UF/IFAS
El método de control más efectivo es realizar una o dos aplicaciones de $0.75 \%-1.5 \%$ de aceite hortícola cuando los árboles están inactivos (Horton et al. 2015). El aceite matará a los machos, a las hembras adheridas y a las crías movibles antes de que se adhieran al árbol. Es crítico asperjar los árboles todos los años, incluso cuando se establece por primera vez. El mejor método de aspersión es usar una pistola de mano a 300-500 psi y mojar completamente todas las áreas del árbol. El aerosol debe penetrar en las grietas de la corteza y aplicarse hasta que escurra. Los aspersores de aire forzado a menudo se usan en huertos grandes, pero es importante tener condiciones sin viento, usar velocidades de avance lentas (125-150 gal/acre), boquillas grandes y buenos patrones de aspersión. Las aplicaciones de aceite no deben realizarse si las temperaturas nocturnas caen por debajo de $28^{\circ} \mathrm{F}$ durante los siguientes 4 días a la aplicación. Del mismo modo, el aceite no debe aplicarse si las temperaturas diurnas sobrepasan los $85^{\circ} \mathrm{F}$. El aceite se extiende y se aplica más fácilmente cuando las temperaturas son superiores a $60^{\circ} \mathrm{F}$. Aplique aceite solo cuando no sea probable que llueva durante las próximas 24 horas.

La aspersión debe realizarse después de la poda de invierno ya que la cobertura será más efectiva. Las infestaciones abundantes requieren dos aplicaciones de aceite. Varias capas de escama tendrán insectos uno encima del otro, por lo tanto, la primera aplicación solo matará la capa superior. En este caso, la primera aplicación se aplica en noviembre o diciembre antes de la aplicación de enero a febrero, o dos semanas después de la de enero. Si la aplicación se realiza a finales del otoño, los árboles deben podarse temprano. Las recomendaciones para la aplicación se pueden encontrar en Insect Management in Peaches en https://edis.ifas.ufl. edu/ig075 o en la Guía de cultivo y manejo de plagas de durazno, nectarina y ciruela del sureste (https://secure.caes. uga.edu/extension/publications/files/pdf/B\%201171_12. PDF).

La escama de durazno blanco (Pseudaulacaspis pentagona) tiene un amplio rango de hospederos, incluido el lciruelo. Se puede encontrar en troncos y ramas de durazno, nectarino y en ocasiones, ciruelo. La escama del durazno blanco se puede detectar fácilmente a fines del verano y el otoño por las poblaciones masculinas blancas como la nieve ubicadas cerca de las colonias femeninas (Figura 18). A este punto del año, las poblaciones aumentan y los árboles están perdiendo follaje, lo que facilita encontrar a las escamas. Las hembras aparecen como puntos blancos elevados, $1 / 16 \mathrm{a}$ $1 / 8$ pulgadas de diámetro, con un punto oscuro en el centro. Este insecto puede ser debilitante para las ciruelas. El mejor control es el uso de aceite en aerosol durante los meses 
de invierno cuando los árboles están inactivos, como se discutió en la sección de la escama de San José.

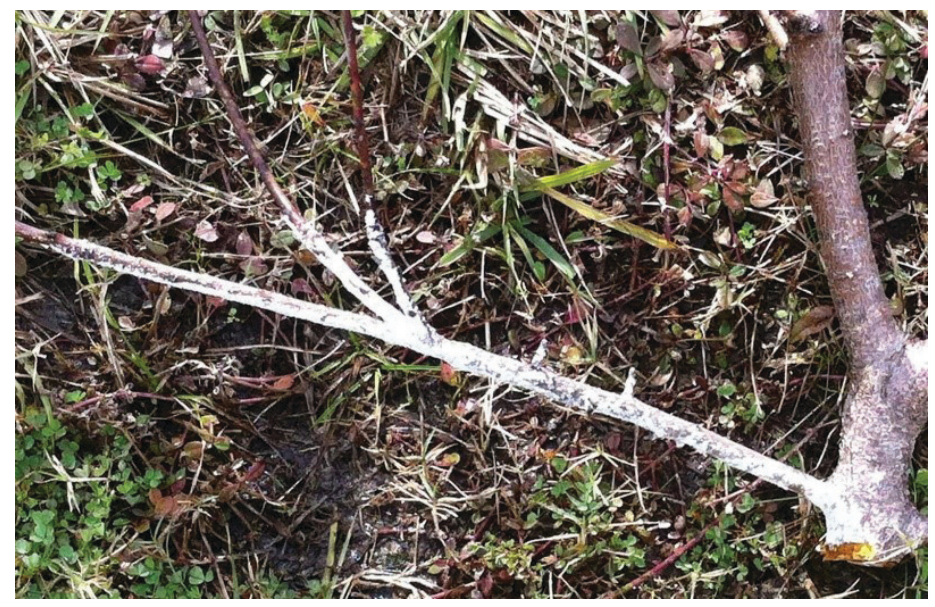

Figura 18. Población abundante de escama blanca del durazno. Observe la apariencia nevada.

Créditos: M. Olmstead, UF/IFAS

Perforadores o barrenadores de árboles. El barrenador del duraznero (S. exitiosa) y el barrenador pequeño del duraznero (Synanthedon pictipes) son plagas potenciales del ciruelo. La gomosis acompañada de excremento de insectos, o la presencia de aserrín dentro de una masa de goma, es un indicador de la presencia de barrenadores. El barrenador puede exponerse cavando debajo de la corteza ubicada detrás de la masa de goma en donde en túneles, el gusano blanco con forma de oruga se alimenta (Figura 19). Cuando se encuentran, los barrenadores pueden ser destruidos a mano. En plantaciones comerciales, se pueden aplicar insecticidas en el tronco y otras áreas donde se alimentan estos insectos (Horton et al. 2015). Por lo general, en Florida, el barrenador del duraznero es más común y se encuentra en el tronco cerca del nivel del suelo. Los barrenadores prefieren la madera del duraznero a la del ciruelo, y dado que la mayoría de los ciruelos se injertan en el portainjerto de durazno, los barrenadores suelen estar en el portainjerto de durazno antes de la unión del injerto y debajo de las ramas de soporte. Para obtener más información sobre los barrenadores, consulte la publicación Peachtree Borers in the Home and Commercial Peach Orchard en https://edis.ifas.ufl.edu/in489. Las recomendaciones de aplicación se pueden encontrar en Insect Management in Peaches en https://edis.ifas.ufl.edu/ig075 o en la Guía de cultivo y manejo de plagas de durazno, nectarina y ciruela del sureste (https://secure.caes.uga.edu/extension/ publications/files/pdf/B\%201171_12.PDF).

Los ácaros araña de dos puntos (Tetranychus urticae) y el ácaro rojo europeo (Panonyochus ulmi) a veces pueden acumularse en ciruelos durante el clima seco de abril a junio. Tienen menos de $1 / 16$ pulgadas de diámetro y son de color naranja a rojo. Los enemigos naturales (incluyendo una especie de mariquita importada, Harmonia acyridis) a menudo pueden mantener los ácaros bajo control. Los pesticidas para control no deben considerarse a menos que las poblaciones acumulen más de 10 ácaros por hoja. Las recomendaciones de aspersión se pueden encontrar en Insect Management in Peaches en https://edis.ifas.ufl. edu/ig075 o en la Guía de cultivo y manejo de plagas de durazno, nectarina y ciruela del sureste (https://secure.caes. uga.edu/extension/publications/files/pdf/B\%201171_12. PDF).

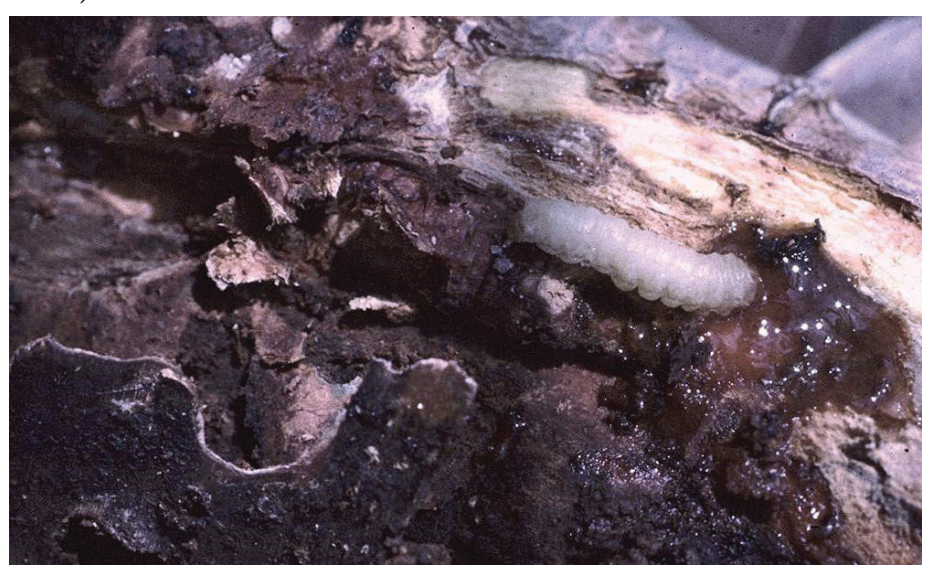

Figura 19. Barrenador menor del durazno con túneles y gomas que contienen excremento.

Créditos: P. Miller, UF/IFAS

Las chinches apestosas y otros insectos que deforman la fruta (incluidas muchas especies de chinche Lygus, chinches apestosas y bichos de patas de hoja) pueden causar daños considerables a la fruta en desarrollo. Estos son insectos chupadores medianos a grandes $(3 / 8$ a $3 / 4$ pulgadas de largo) que causan deformidades de la fruta y reducen la capacidad de comercialización. Los insectos deformadores pueden ser especialmente dañinos para la fruta durante los 14 días previos a la cosecha porque el sondeo que realizan al alimentarse, puede provocar infecciones de podredumbre morena. Controlar las malezas suculentas de las que se alimentan estos insectos también ayudará a reducir las poblaciones. Sin embargo, no es raro ver que muchos de estos insectos de una segunda o tercera generación aparecen cerca del periodo de cosecha de la fruta. Varias aplicaciones adecuadamente sincronizadas cuando una gran cantidad de estos insectos se están alimentando en los árboles harán mucho para ayudar en su control. Se pueden considerar trampas o medidas de control biológico. Se puede encontrar más información en el documento Monitoring Stink Bugs with the Florida Stink Bug Trap en http://blogs.ifas.ufl.edu/ pestalert/2018/09/03/bmsb_florida/. Las recomendaciones de aspersión se pueden encontrar en Insect Management in Peaches en https://edis.ifas.ufl.edu/ig075 o en la Guía de cultivo y manejo de plagas de durazno, nectarina y ciruela 
del sureste (https://secure.caes.uga.edu/extension/publications/files/pdf/B\%201171_12.PDF).

El trip occidental de la flor (Frankliniella occidentalis) es un insecto diminuto, apenas visible, que puede causar imperfecciones en las nectarinas y las ciruelas. El control de estos insectos en el jardín rara vez se justifica, pero el control a nivel comercial a veces es necesario para producir fruta libre de manchas. Las recomendaciones de aspersión se pueden encontrar en Insect Management in Peaches en https://edis.ifas.ufl.edu/ig075 o en la Guía de cultivo y manejo de plagas de durazno, nectarina y ciruela del sureste (https://secure.caes.uga.edu/extension/publications/files/ pdf/B\%201171_12.PDF).

\section{Enfermedades}

Bacteriosis, causada por Xanthomonas campestris pv. pruni, ataca principalmente las hojas, pero también infecta brotes y frutos. La infección de la hoja comienza con manchas acuosas que cambian de amarillo verdoso a morado a marrón oscuro y luego eventualmente se caen y forman un agujero. En la fruta, se producen lesiones y gomosis. Los chancros de las ramas pequeñas también pueden causar una apariencia nudosa y pueden persistir varios años hasta la muerte de las ramitas. El mejor control es utilizar cultivares resistentes a la bacteriosis como la serie de ciruelas 'Gulf' lanzada por la Universidad de Florida.

La gomosis fúngica es causada por Botyrosphaeria spp. y es una enfermedad fúngica que causa gummosis en el tronco y las ramas de soporte (Figura 20). Esta enfermedad se puede minimizar manteniendo un buen saneamiento. Elimine toda la fruta en la cosecha y elimine toda la madera de poda del entorno del huerto porque este organismo puede esporular a partir del tejido vegetal en descomposición.

Para obtener más información sobre la gomosis fúngica en el duraznero, consulte Fungal Gummosis in Peach en https:// edis.ifas.ufl.edu/hs1265.

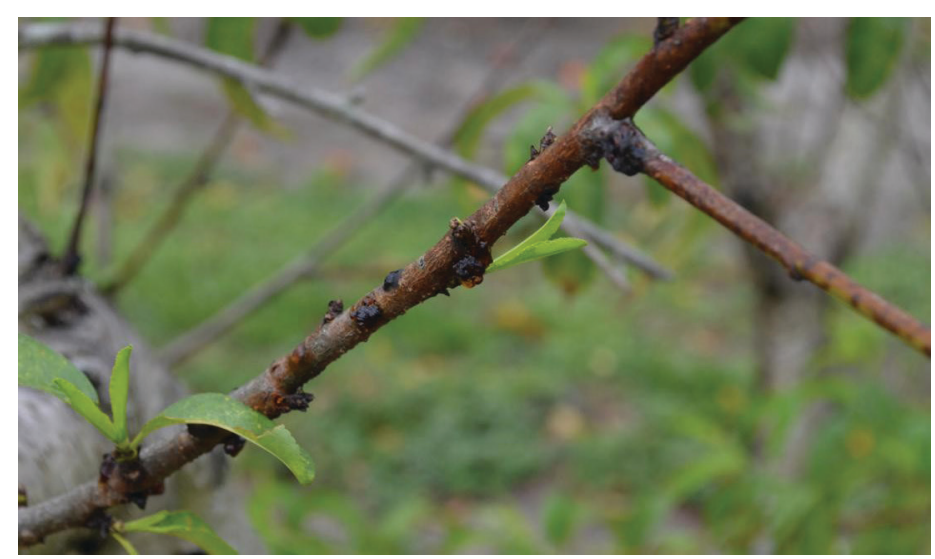

Figura 20. Gomosis en durazno causada por Botyrosphaeria dothidea. Créditos: M. Olmstead, UF/IFAS
La podredumbre morena es causada por el hongo Monilina fructicola. La podredumbre morena puede atacar flores, frutos, hojas y tallos. Sobrevive el invierno en tallos infectados y fruta momificada. La podredumbre morena puede ser un problema durante el clima húmedo, pero la presión de la enfermedad es menos severa que en el durazno. Las infecciones aparecerán como masas de esporas de color marrón a gris pardo en el tejido infectado. Las prácticas diseñadas para aumentar el flujo de aire en todo el dosel de los árboles y eliminar el tejido infectado del año anterior reducirán la incidencia de podredumbre morena. No hay cultivares de ciruela resistentes a la podredumbre morena, y pueden ser necesarias aspersiones de fungicidas durante el clima húmedo.

La muerte descendente es causada por el hongo Armillaria mellea y/o A. tabescans. La enfermedad es especialmente problemática en lugares que albergan restos de raíces de roble, nogal o árboles forestales. Por lo tanto, es mejor plantar en un terreno que ha sido despejado de árboles durante al menos 20 años. La muerte radicular de los ciruelos suele ir acompañada de cuerpos de hongos que pueden verse debajo de la copa de los árboles. No hay una buena fuente de control químico, pero hay portainjertos tolerantes disponibles.

La escaldadura de la hoja del ciruelo es causada por la bacteria Xylella fastidiosa, y la enfermedad es trasmitida por saltahojas (o chicharritas). Antes de plantar, retire los ciruelos silvestres a varios cientos de yardas de su posible huerto. Los primeros síntomas son un color amarillento alrededor de las márgenes de las hojas y un ennegrecimiento y desecación de las puntas de las hojas. Esto es seguido por la muerte de las puntas de las ramas y la muerte del árbol. La mejor solución es usar cultivares resistentes a la escaldadura de hojas del ciruelo como la serie de ciruelas 'Gulf' lanzada por la Universidad de Florida.

\section{Conejos y Ciervos}

Los conejos y los ciervos pueden ser serios impedimentos para el establecimiento de ciruelos. Ambos animales se comen la corteza, especialmente en la primavera, y los ciervos rompen las ramas. En el momento de la siembra, se pueden usar varias guardas para protección contra conejo o papel aluminio para impedir el daño causado por conejos, mientras que para ciervos se puede requerir una cerca en donde la presión de ciervos es alta. En el área rural o en áreas donde existen poblaciones de ciervos, puede que no sea posible cultivar ciruelos sin protegerlos de este animal. 


\section{Referencias}

Blaauw, B., P. Brannen, B. Bellinger, D. Lockwood, and D. Ritchie. 2018. Southeastern Peach, Nectarine and Plum Pest Management and Culture Guide. https://secure.caes.uga. edu/extension/publications/files/pdf/B\%201171_12.PDF

Jones, J. B, B. Wolf, and H. A. Mills. 1991. Plant Analysis Handbook, A Practical Sampling, Preparation, Analysis, and Interpretation Guide. Micro-Macro Publishing, Inc. ISBN1-878148-001.

Mizell, R. 2015. Insect Management in Peaches. ENY-801. Gainesville: University of Florida Institute of Food and Agricultural Sciences. https://edis.ifas.ufl.edu/ig075 